\title{
Fibrose cística: histórico e principais meios para diagnóstico
}

\author{
Cystic fibrosis: history and main means for diagnosis
}

Fibrosis quística: historia y principales medios para el diagnóstico

Maria Natália Alves Ribeiro ORCID: https://orcid.org/0000-0001-6317-0320 Centro Universitário de Juazeiro do Norte, Brasil

E-mail: nataliarte14@gmail.com

José Leonardo Gomes Coelho ORCID: https://orcid.org/0000-0001-6028-0807 Centro Universitário Leonardo da Vinci, Brasil

E-mail: leonardocoelho999@gmail.com

Natália dos Santos Almeida ORCID: https://orcid.org/0000-0002-3766-5300 Centro Universitário de Juazeiro do Norte, Brasil E-mail: nattyalmeida49@gmail.com

Renata Vilar Bernardo

ORCID: https://orcid.org/0000-0001-7011-9857 Centro Universitário Leonardo da Vinci, Brasil E-mail:renatavilarb@gmail.com

Camila Florinda Nascimento Martins ORCID: https://orcid.org/0000-0002-8328-5480 Centro Universitário de Juazeiro do Norte, Brasil E-mail: camilafnm30@gmail.com

Eugênia Leopoldina Ferreira ORCID: https://orcid.org/0000-0002-0843-7632 Centro Universitário de Juazeiro do Norte, Brasil E-mail: eugenialeopoldinaferreira@gmail.com

Yolanda Gomes Duarte

ORCID: https://orcid.org/0000-0002-1908-4385

Centro Universitário Dr. Leão Sampaio, Brasil

E-mail: yolanda.duarte1963@gmail.com

Maria Eduarda Correia dos Santos ORCID: https://orcid.org/0000-0002-7210-5624

Centro Universitário Dr. Leão Sampaio, Brasil E-mail: eduardacorreia92@gmail.com

Carla Jamily Cabral Pereira

ORCID: https://orcid.org/0000-0001-5623-7742

Centro Universitário de Juazeiro do Norte, Brasil E-mail: jamilycabral2014@gmail.com

Iannaele Oliveira do Vale Batista ORCID: https://orcid.org/0000-0003-4580-5059 Centro Universitário de Juazeiro do Norte, Brasil E-mail: iannaeleoliveira10@gmail.com

Lauanda Nogueira Cândido

ORCID: https://orcid.org/0000-0001-5681-2903

Centro Universitário de Juazeiro do Norte, Brasil

E-mail: lauandacandido@gmail.com

Willma José de Santana

ORCID: https://orcid.org/0000-0003-2733-2892

Faculdade de Odontologia, Brasil

E-mail:wjsantana@hotmail.com

Dayse Christina Rodrigues Pereira Luz

ORCID: https://orcid.org/0000-0002-5719-3574

Centro Universitário Saúde do ABC, Brasil E-mail: dayse.dcrp@hotmail.com

\section{Resumo}

A Fibrose cística (FC) é uma doença rara que se manifesta ainda na infância ou na adolescência, é altamente letal e multissistêmica, gerada através da mutação no gene que codifica a Proteína Reguladora da Condutância Transmembrana da Fibrose Cística, o que provoca aumento da viscosidade do muco no corpo humano e necessita-se de formas de diagnóstico para delimitar o tratamento a ser seguido. O objetivo deste estudo foi verificar o histórico da 
fibrose cística e identificar alguns dos principais métodos de diagnóstico dessa patologia.Trata-se de uma revisão integrativa da literatura, realizada nas bases de dados Scientific Eletronic Library Online (SciELO), Medical Literature Analysis and Retrieval System Online (MedLine/PUBMED) e Literatura Latino-americna e do Caribe em Ciências da Saúde (LILACS), utilizando os descritores em DeCS: Fibrose Cística, diagnóstico, histórico, com uso do operador Booleano AND. A seleção respeitou critérios de inclusão e exclusão dos artigos disponíveis de forma completa e gratuita, entre os anos de 2015 e 2020, nos idiomas português, inglês e espanhol. Os estudos inconclusivos, repetitivos e as revisões integrativas foram excluídos durante a coleta para a pesquisa em questão. Foram encontrados cerca de 459 estudos relacionados à fibrose cística, dos quais 26 artigos cumpriram os critérios previamente determinados e foram incluídos na revisão. Segundo os métodos de diagnósticos encontrados, o padrãoouro é o Teste do Suor. A fibrose cística é uma doença urgente e crônica, que faz vítimas em todo o mundo e que precisa de diagnóstico precoce a fim de se aumentar a sobrevida do paciente.

Palavras-chave: Fibrose cística; Diagnóstico; Doenças raras; Histórico.

\begin{abstract}
Cystic fibrosis (CF) is a rare disease that manifests itself in childhood or adolescence, it is highly lethal and multisystemic, generated through the mutation in the gene that encodes the Cystic Fibrosis Transmembrane Conductance Regulatory Protein, which causes increased viscosity mucus in the human body and forms of diagnosis are required to define the treatment to be followed. The objective of this study was to verify the history of cystic fibrosis and to identify some of the main methods of diagnosis of this pathology. It is an integrative literature review, carried out in the Scientific Electronic Electronic Library Online (SciELO), Medical Literature Analysis and Retrieval databases System Online (MedLine / PUBMED) and Latin American and Caribbean Literature in Health Sciences (LILACS), using the descriptors in DeCS: Cystic Fibrosis, diagnosis, history, using the Boolean AND operator. The selection followed criteria for inclusion and exclusion of articles available completely and free of charge, between the years 2015 and 2020, in Portuguese, English and Spanish. Inconclusive, repetitive studies and integrative reviews were excluded during collection for the research in question. About 459 studies related to cystic fibrosis were found, of which 26 articles met the previously determined criteria and were included in the review. According to the diagnostic methods found, the gold standard is the Sweat Test. Cystic fibrosis is an urgent and chronic disease that causes victims worldwide and that needs early diagnosis in order to increase patient survival.
\end{abstract}

Keywords: Cystic fibrosis; Diagnosis; Rare diseases; Historic.

\title{
Resumen
}

La fibrosis quística (CF) es una enfermedad rara que se manifiesta incluso en la infancia o la adolescencia, es altamente letal y multisistémica, generada a través de la mutación en el gen que codifica la Proteína Reguladora de Conductancia Transmembrana de la Fibrosis Quística, que causa una mayor viscosidad de la mucosidad en el cuerpo humano y requiere formas diagnósticas para delimitar el tratamiento a seguir. El objetivo de este estudio fue verificar la historia de la fibrosis quística e identificar algunos de los principales métodos de diagnóstico de esta patología. Se trata de una revisión integradora de la literatura, realizada en las bases de datos Scientific Electronic Library Online (SciELO), Medical Literature Analysis and Retrieval System Online (MedLine/PUBMED) y Latin-Americna and Caribbean Literature in Health Sciences (LILACS), utilizando los descriptores de DeCS: Fibrosis quística, diagnóstico, historia, con el uso del operador booleano AND. La selección respetaba los criterios de inclusión y exclusión de los artículos disponibles total y gratuitamente, entre los años 2015 y 2020, en los idiomas portugués, inglés y español. Durante la recopilación se excluyeron estudios no concluyentes, repetitivos y revisiones integrativas para la investigación en cuestión. Se encontraron aproximadamente 459 estudios relacionados con la fibrosis quística, de los cuales 26 artículos cumplían los criterios previamente determinados y se incluyeron en la revisión. Según los métodos de diagnóstico encontrados, el estándar de oro es la prueba de sudor. La fibrosis quística es una enfermedad urgente y crónica que causa a las víctimas en todo el mundo y necesita un diagnóstico precoz para aumentar la supervivencia del paciente.

Palabras clave: Fibrosis quística; Diagnóstico; Enfermedades raras; Histórico.

\section{Introdução}

A Fibrose Cística (FC) ou Mucoviscidose é uma patologia geneticamente hereditária, caracterizada pelo aumento da viscosidade e da quantidade de muco secretado, e é uma doença de ordem autossômica recessiva, que é resultado da perturbação na Proteína Reguladora da Condutância Transmembrana da Fibrose Cística (Cystic Fibrosis Transmembrane Condutance Regulator) - a CFTR. Essa doença rara provoca inúmeras consequências para a saúde do seu portador e para a convivência familiar, o que leva a urgência de diagnóstico precoce para a iniciação do tratamento (Lubovich; et al, 2019).

A CTFR é a proteína que regula o balanço hidroeletrolítico das células do trato respiratório, do pâncreas, do fígado e 
do trato reprodutivo ao atuar como uma proteína transportadora do tipo canal dos íons cloreto, desempenhando um papel importantíssimo no organismo humano. Entretanto, quando há uma mutação no gene que regula essa proteína, há o aumento significativo da viscosidade da mucosa do pulmão, fígado, pâncreas e intestino, de forma a provocar os sintomas característicos da fibrose cística que inclui doença pulmonar obstrutiva crônica, fibrose hepática e pancreática (Al-Abadi; et al, 2019).

A FC foi descrita pela primeira vez em 1938 pelo patologista Dorothy Andersen, já o gene responsável por essa doença foi localizado e identificado em 1989 por John Richard Riordan, Francis Collins e Lap-Chee Tsui, e está no sétimo cromossomo humano na posição 7q13, descobrindo assim a primeira mutação responsável pela fibrose cística. Através dos estudos de pesquisadores, inúmeras formas de diagnóstico foram desenvolvidas, porém não se tem uma cura para a FC (Bepari, et al, 2015)

A natureza dessa doença é multissistêmica, ou seja, tem a capacidade de afetar todos os sistemas do organismo humano, principalmente o respiratório, o gastrointestinal e o reprodutor. Ademais, ela é uma doença crônica, progressiva e altamente letal, que se manifesta especialmente já na infância e na adolescência, sendo que o diagnóstico precoce e o tratamento são as principais ferramentas capazes de aumentar a sobrevida do paciente. Todavia, o paciente portador de FC necessita de um cuidado complexo e persistente, de modo que ultrapasse as paredes dos hospitais e centros de tratamento, realizado por todos os membros que integram a vida do paciente, particularmente a família, que serão os responsáveis pela facilitação do processo de adequação e compreensão da nova realidade pela criança portadora de FC (Alves \& Bueno, 2018)

A fibrose cística resulta de uma disfunção genética que afeta as glândulas exócrinas e é a doença autossômica recessiva mais comum em caucasianos, que se manifesta em cerca de um para cada 2500 nascidos vivos e um em cada 22 indivíduos possuem o gene. No Brasil, a FC possui uma estimativa média de aproximadamente 1: 9600 nascimentos. No Reino Unido, em afro-americanos, asiáticos-americanos e na Índia essa estimativa é de 1 em cada 2500 crianças, 1 em 15.000, $1 \mathrm{em}$ 31.000 e 1 em 40.000, respectivamente. Em decorrência dos avanços no diagnóstico e no tratamento, a sobrevida dos pacientes aumentou expressivamente, com mediana atual de 38 anos em países europeus e americanos (Adde, 2015).

As sintomatologias apresentadas pelos pacientes variam em decorrência da progressão da doença e do estado imunológico do paciente. As diversas manifestações clínicas podem ocorrer no pâncreas, no trato intestinal, no fígado, nas glândulas sudoríparas, no aparelho reprodutor e acometimento pulmonar grave. Podem apresentar tórax enfisematoso, broncorréia purulenta, frequência respiratória aumentada, dificuldade expiratória, cianose periungueal, tosse, fadiga, dores abdominais, infecção crônica das vias aéreas bacterianas, inflamação neutrofílica proeminente, vias aéreas obstruídas por muco e bronquiectasia progressiva caracterizam doença pulmonar avançada por fibrose cística, que causa a maior morbimortalidade, além disso doenças psicológicas podem aparecer em decorrência do desgaste emocional que a doença provoca (Reisinho; Gomes, 2016).

Assim, a fibrose cística é uma doença urgente que necessita sempre mais de pesquisas e estudos que possibilitem aos seus portadores o aumento de sua expectativa de vida e a melhora dessa, ao diminuir as complicações geradas por tal patologia. As formas de diagnóstico são necessárias para identificação precoce dessa patologia com a finalidade de tornar o tratamento eficaz. Concomitantemente, conhecer o histórico da doença pode ajudar a promover a adesão do paciente às alternativas farmacológicas existentes (Ferreira, Chaves \& Costa, 2019).

Diante do exposto, este estudo teve como objetivo identificar, através de uma revisão integrativa da literatura, os principais meios de diagnóstico da Fibrose Cística e as consequências dessa doença para os seus portadores. 


\section{Metodologia}

Trata-se de uma revisão integrativa da literatura, de abordagem qualitativa, seguindo as seis etapas: elaboração da pergunta norteadora, descrição dos critérios de inclusão e exclusão dos artigos, busca na base de dados, análise dos dados obtidos, discussão e apresentação dos resultados (Mendes, Silveira \& Galvão, 2008).

Elaborou-se a seguinte pergunta norteadora: Quais são as evidências apresentadas na literatura sobre principais meios de diagnóstico da Fibrose Cística e as consequências dessa doença para os seus portadores?

Os critérios de inclusão utilizados foram: 1) se o artigo estava disponível na íntegra; 2) se estavam em português, inglês ou espanhol; 3) com a data de sua publicação entre os anos de 2015 a 2020. O critério de exclusão se deu aos artigos duplicados, aos que não fossem originais, aos estudos inconclusivos ou descontextualizados.

A busca dos artigos foi realizada através das bases de dados da Scientific Eletronic Library Online (SciELO), Medical Literature Analysis and Retrieval System Online (MedLine) e Literatura Latino-americna e do Caribe em Ciências da Saúde (LILACS). Na definição dos descritores foi empregado o Descritores em Ciências da Saúde (DeCS), um dicionário de indexação de termos criado pela Bireme. O período de busca foi realizado durante os meses de maio e junho de 2020.

Para a realização dessa revisão, utilizou-se o operador booleano AND, na associação dos seguintes descritores: Fibrose cística; diagnóstico AND fibrose; histórico da fibrose. Posteriormente, foi promovida a triagem dos trabalhos através da leitura do resumo de cada um. Foi utilizada uma planilha matriz para ter o controle de todos os artigos encontrados nas bases, com as descriminações: autor e ano, título, jornal, amostra, país, principais achados, conclusão, base de dados, motivo de exclusão.

Algumas etapas foram adotadas, tais como: elegibilidade dos artigos e a análise dos achados para estabelecer quais artigos seriam incluídos através da leitura prévia do resumo, com a finalidade de verificar sua relação com o tema para assim, proceder com a leitura do artigo na íntegra.

Os artigos que permaneceram na amostra após a aplicação dos critérios de identificação e seleção tiveram impressão e foram analisados por meio da leitura crítica do estudo na íntegra. Concomitantemente, os principais pontos abordados com relevância nesses trabalhos permaneceram nesta revisão.

A Figura 1 apresenta o fluxograma com as etapas de seleção dos artigos das bases de dados. 
Figura 1: Fluxograma da seleção dos estudos. Juazeiro do Norte, CE, Brasil, 2020.
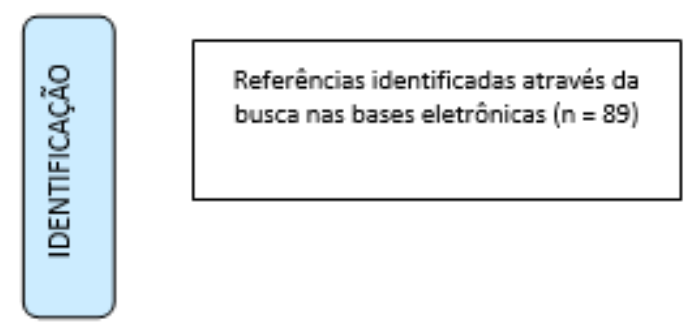

Referências identificadas por busca manual em outras fontes $(n=0)$
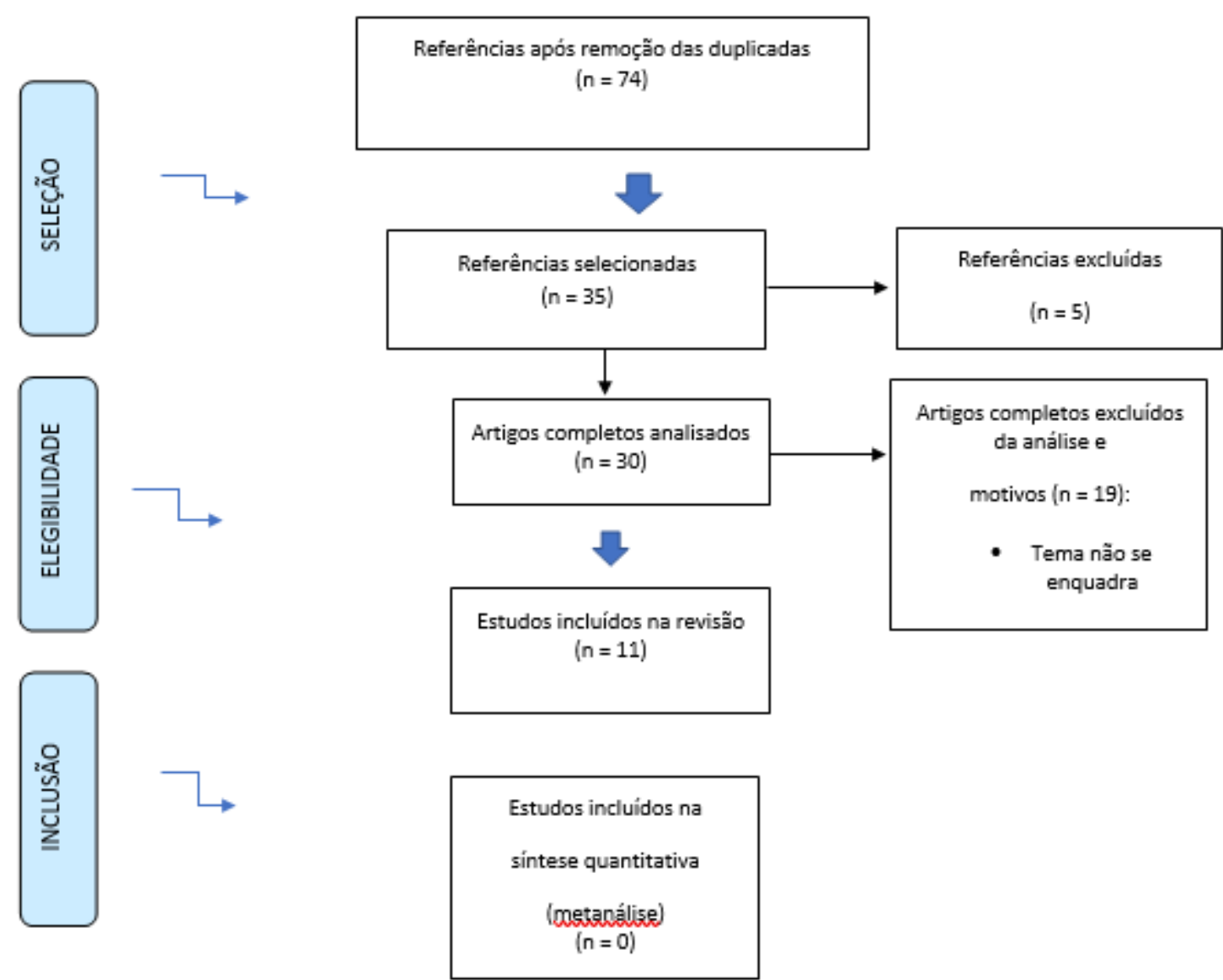

Fonte: Autores.

Empregados os descritores mencionados, apareceram 89 artigos que faziam referência aos termos procurados. Foram removidos 74 artigos, pois se encontravam duplicados. Os resumos foram analisados, e os que faziam referência ao tema contemplaram a amostra. Permaneceram 30 estudos para a leitura na íntegra. Destes, 19 estudos foram excluídos, pois nãofaziam referência ao tema central da pesquisa, restando 11 artigos.

\section{Resultados e Discussão}

A partir dos artigos selecionados, foi-se construída uma tabela contendo nome dos autores, ano das publicações, título, em qual revistas foram publicados os artigos e um resumo simples dos artigos lidos. 
Tabela 1: Artigos utilizados no estudo com o objetivo e os principais resultados, 2020.

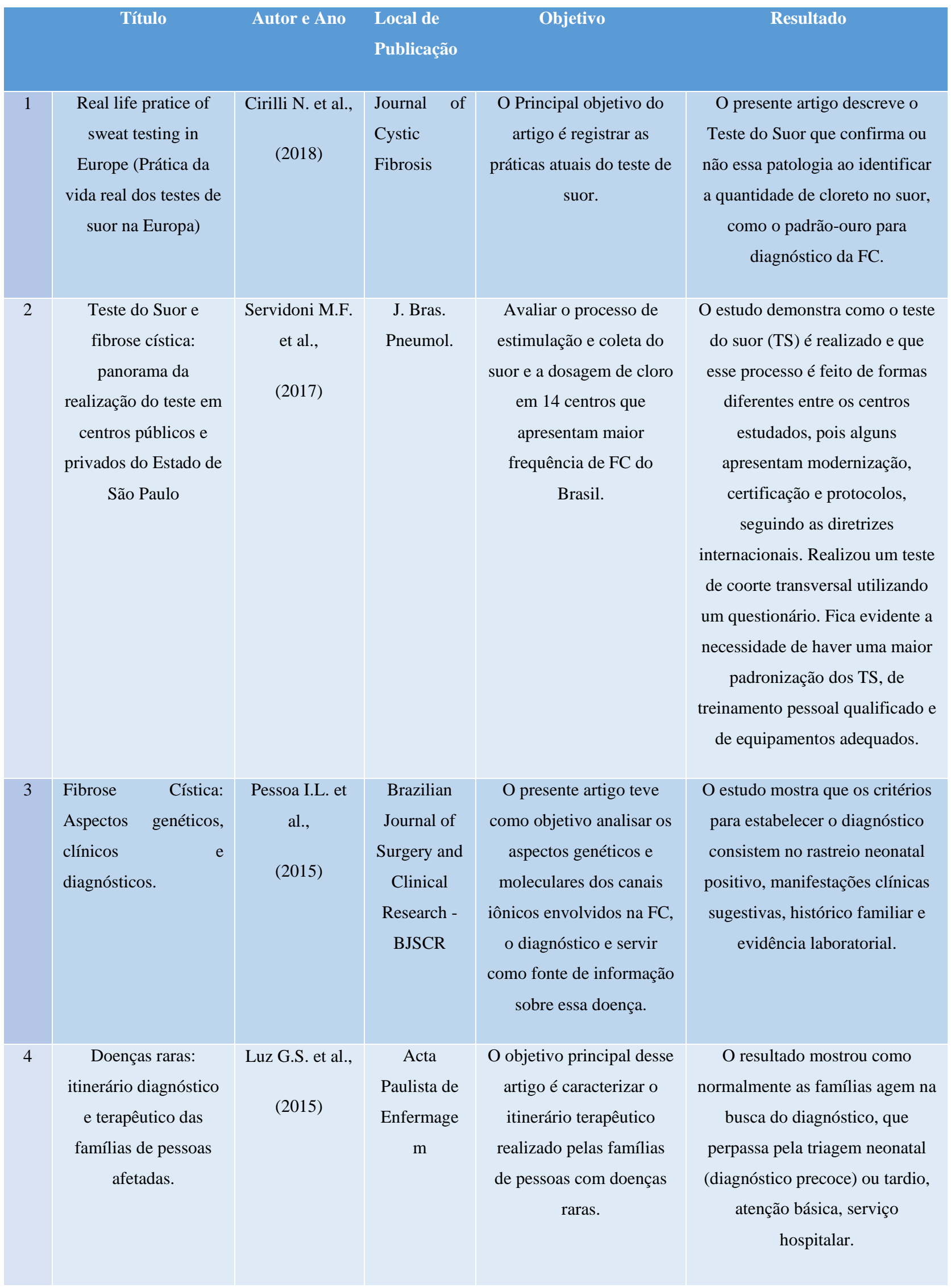




\begin{tabular}{|c|c|c|c|c|c|}
\hline 5 & $\begin{array}{l}\text { Clinical expression } \\
\text { of cystic fibrosis in a } \\
\text { large cohort of Italian } \\
\text { siblings } \\
\text { (Expressão clínica da } \\
\text { fibrose cística em uma } \\
\text { grande coorte de } \\
\text { irmãos italianos) }\end{array}$ & $\begin{array}{l}\text { Terlizzi V. et } \\
\text { al., } \\
\text { (2018) }\end{array}$ & $\begin{array}{c}\text { BMC } \\
\text { Pulmonary } \\
\text { Medicine }\end{array}$ & $\begin{array}{l}\text { Objetivou-se discutir a } \\
\text { expressão da fibrose } \\
\text { cística e meio de } \\
\text { diagnóstico através de um } \\
\text { estudo de coorte em } \\
\text { irmãos italianos. } \\
\text {. }\end{array}$ & $\begin{array}{l}\text { O estudo concluiu que é preciso } \\
\text { em alguns casos realizar o } \\
\text { sequenciamento genético e } \\
\text { examinar o painel de mutações } \\
\text { rearranjos, analisando-se a } \\
\text { genética familiar. }\end{array}$ \\
\hline 6 & $\begin{array}{c}\text { Concentração de } \\
\text { cloreto e íons de sódio } \\
\text { na saliva e no suor } \\
\text { como método para } \\
\text { diagnosticar fibrose } \\
\text { cística. }\end{array}$ & $\begin{array}{l}\text { Gonçalves } \\
\text { A.C. et al., } \\
\text { (2019) }\end{array}$ & $\begin{array}{c}\text { J Pediatr } \\
\text { (Rio J) }\end{array}$ & $\begin{array}{l}\text { O principal objetivo desse } \\
\text { estudo é verificar a } \\
\text { correlação entre a } \\
\text { concentração de cloreto } \\
\text { de saliva e a de suor em } \\
\text { pacientes com FC como } \\
\text { meio de diagnóstico. }\end{array}$ & $\begin{array}{l}\text { Os pacientes com fibrose cística } \\
\text { apresentam maior concentração } \\
\text { de cloreto e de sódio no suor do } \\
\text { que indivíduos saudáveis. A } \\
\text { análise foi feita utilizando o } \\
\text { procedimento mercurimétrico de } \\
\text { Schales \&Schales e fotometria } \\
\text { de chama. }\end{array}$ \\
\hline 7 & $\begin{array}{c}\text { O uso da } \\
\text { ultrassonografia para } \\
\text { avaliar a espessura } \\
\text { muscular e a gordura } \\
\text { subcutânea em } \\
\text { crianças e } \\
\text { adolescentes com } \\
\text { fibrose cística }\end{array}$ & $\begin{array}{l}\text { Souza R.P. et } \\
\text { al., } \\
\text { (2018) }\end{array}$ & $\begin{array}{l}\text { Rev Paul } \\
\text { Pediatr. }\end{array}$ & $\begin{array}{l}\text { O objetivo desse estudo } \\
\text { foi comparar a espessura } \\
\text { muscular e a gordura } \\
\text { subcutânea em pacientes } \\
\text { com FC e controles } \\
\text { saudáveis utilizando } \\
\text { ultrassonografia. }\end{array}$ & $\begin{array}{l}\text { Concluiu-se que a os pacientes de } \\
\text { FC apresentam menor índice de } \\
\text { massa corporal, o que auxilia no } \\
\text { diagnóstico. }\end{array}$ \\
\hline 8 & $\begin{array}{c}\text { Italian external } \\
\text { quality assessment } \\
\text { program for cystic } \\
\text { fibrosis sweat } \\
\text { chloride test: a } 2015 \\
\text { and } 2016 \text { results } \\
\text { comparison. } \\
\text { (Programa italiano de } \\
\text { avaliação de } \\
\text { qualidade externa } \\
\text { para teste de cloreto } \\
\text { de suor de fibrose } \\
\text { cística: uma } \\
\text { comparação de } \\
\text { resultados de } 2015 \text { e } \\
\text { 2016.) }\end{array}$ & $\begin{array}{l}\text { Salvatore M. } \\
\text { et al., } \\
\text { (2017) }\end{array}$ & $\begin{array}{c}\text { Ann Ist } \\
\text { Super Sanita }\end{array}$ & $\begin{array}{l}\text { O objetivo desse estudo é } \\
\text { comparar os resultados } \\
\text { dos testes de diagnóstico } \\
\text { de FC entre } 2015 \text { e } 2016 .\end{array}$ & $\begin{array}{c}\text { O presente artigo mostra o } \\
\text { registro de realização do } \\
\text { diagnóstico de FC em treze e } \\
\text { quinze laboratórios ao longo } \\
\text { desses anos, utilizando o teste do } \\
\text { suor. }\end{array}$ \\
\hline
\end{tabular}




\begin{tabular}{|c|c|c|c|c|c|}
\hline 9 & $\begin{array}{c}\text { Relato de Caso: } \\
\text { fibrose cística e a } \\
\text { importância do } \\
\text { diagnóstico precoce }\end{array}$ & $\begin{array}{l}\text { Machado L.N. } \\
\text { et al., } \\
\text { (2020) }\end{array}$ & $\begin{array}{l}\text { Revista } \\
\text { Unilago }\end{array}$ & $\begin{array}{c}\text { Relatar e verificar a } \\
\text { importância da realização } \\
\text { do diagnóstico precoce. }\end{array}$ & $\begin{array}{c}\text { O diagnóstico é baseado em } \\
\text { sinais clínicos e sintomas } \\
\text { consistentes com a doença e } \\
\text { evidência da mutação na CFTR. } \\
\text { A triagem neonatal é realizada } \\
\text { através da quantificação do } \\
\text { tripsinogênio imunorreativo. }\end{array}$ \\
\hline 10 & $\begin{array}{c}\text { Relato de caso: } \\
\text { diagnóstico e manejo } \\
\text { de paciente com } \\
\text { fibrose cística em } \\
\text { apresentação } \\
\text { Clássica. }\end{array}$ & $\begin{array}{l}\text { Battestin B. et } \\
\text { al., } \\
\text { (2016) }\end{array}$ & $\begin{array}{l}\text { Revista de } \\
\text { Medicina e } \\
\text { Saúde de } \\
\text { Brasília }\end{array}$ & $\begin{array}{c}\text { Relatar a forma de } \\
\text { diagnóstico da FC e como } \\
\text { deve ser feito o manejo do } \\
\text { paciente acometido por } \\
\text { essa patologia. }\end{array}$ & $\begin{array}{l}\text { As formas de diagnóstico } \\
\text { utilizadas foram a anamnese } \\
\text { completa, o teste do suor, } \\
\text { ultrassonografia de abdome, } \\
\text { radiografia de tórax e } \\
\text { hematócrito. }\end{array}$ \\
\hline 11 & $\begin{array}{c}\text { Prevalência das } \\
\text { doenças detectadas } \\
\text { pelo Teste do Pezinho } \\
\text { no município de } \\
\text { Uruguaiana, RS }\end{array}$ & $\begin{array}{l}\text { Dias A. et al., } \\
\text { (2015) }\end{array}$ & $\begin{array}{l}\text { Periódicos } \\
\text { Unipampa }\end{array}$ & $\begin{array}{l}\text { Identificar as doenças } \\
\text { mais prevalentes } \\
\text { detectadas pelo Teste do } \\
\text { Pezinho em Uruguaiana. }\end{array}$ & $\begin{array}{l}\text { O teste do pezinho pode } \\
\text { identificar cerca de seis doenças, } \\
\text { sendo elas: a fibrose cística ( } 7 \%) \text {, } \\
\text { o hipotireoidismo congênito } \\
(6 \%) \text {, deficiência de biotinidase } \\
(0,2 \%) \text {, a fenilcetonúria ( } 2 \%) \text {, } \\
\text { hiperplasia adrenal congênita } \\
(6 \%) \text { e doença falciforme }(84 \%) \text {. }\end{array}$ \\
\hline
\end{tabular}

Fonte: Dados LILACS, MEDLINE, SCIELO, BVS.

A partir dos artigos estudados, foi feita a divisão em duas categorias, para melhor compreensão acerca do tema, conforme segue na Tabela 2.

Tabela 2: Categorias do tipo de estudo, Brasil, 2020.

$\begin{array}{ll}\text { CATEGORIAS } & \text { ARTIGOS }\end{array}$

\section{Categoria 01: Teste do Suor}

Cirilli N; et al, 2018; Servidoni MF; et al, 2017; Lubovich S; et al, 2019; Pessoa IL; et al, 2015; Terlizzi V; et al, 2018; Salvatore M; et al, 2017; Machado LN; Gomes MG; Alves AB, 2020.

Categoria 02: Métodos capazes de identificar a Fibrose Cística e Confirmar o Teste do Suor.

Terlizzi V; et al, 2018; Gonçalves AC; et al, 2019; Souza RP; et al, 2018

Fonte: Dados LILACS, MEDLINE, SCIELO, BVS (2020).

\section{CATEGORIA 01: Teste do Suor}

A fibrose cística é uma doença de ordem genética e incurável, porém o seu tratamento pode ser realizado para aumentar a sobrevida do paciente, de modo que torna o diagnóstico precoce um aspecto necessário para permitir o aumento dessa sobrevida. Para realizar a identificação de um portador de fibrose cística, alguns métodos de diagnosticar a FC foram desenvolvidos ao longo da evolução histórica da doença, dentre eles, o mais utilizado é o Teste do Suor, que consiste em um 
biomarcador único de alta especificidade e sensibilidade, capaz de medir a concentração de eletrólitos no suor do paciente. Esse teste foi desenvolvido em 1959 por Gibson e Cooke e ainda permanece nos dias atuais como o padrão-ouro para o diagnóstico da FC (Dias; Saatkamp; Manfredini, 2015)

O diagnóstico de FC pelo Teste do Suor é baseado na quantidade de concentração do cloreto atingida durante a medição. Nos valores obtidos, se a marca de íons cloreto for igual ou superior a faixa de $60 \mathrm{mEq} / \mathrm{mL}$, já é um indicativo que aquele indivíduo é portador da FC, pois o valor considerado normal é menor que $30 \mathrm{mEq} / \mathrm{mL}$ e o limítrofe é maior que $30 \mathrm{e}$ menor que $60 \mathrm{mEq} / \mathrm{mL}$, entretanto a quantidade de cloreto pode sofrer alterações em decorrência do reflexo de muitos fatores e de sua interação, como por exemplo o peso do suor, idade, sexo, mutações no regulador da condutância, índice de massa corporal, genes modificados e canais iônicos. Mesmo assim, o teste de suor ainda é o mais utilizado e confiável pelos especialistas para determinação da FC em crianças, adolescentes e adultos (Terlizzi; et al, 2018; Emiralioglu; et al, 2016).

O Teste do Suor é um método clássico que mesmo diante de testes genéticos, mostra ser o mais utilizado, porém não está livre de discussões quanto ao seu uso e sua complexidade, já que para sua realização é necessária a extração do suor de filtros de papel e de gazes para coletá-lo, depois realizar a pesagem das amostras duas vezes e posterior diluição para análise química dos eletrólitos cloro e sódio que apresentam concentração anormal, devido à deficiência da proteína que regula a liberação desses eletrólitos (Domingos; et al, 2015). Contudo, é possível verificar que essa forma de diagnóstico é a principal para dar suporte precoce ao portador de FC, que ao realiza-lo é capaz de obter um resultado seguro sobre sua condição física, seguindo as Diretrizes de Diagnóstico e de Tratamento da Fibrose Cística (Mastella, 2010)

CATEGORIA 02: Métodos capazes de identificar a Fibrose Cística e Confirmar o Teste do Suor

Além do teste do suor, alguns métodos podem ser utilizados para dar suporte e confirmação do resultado obtido ao realizar o teste do suor. Dentre esses métodos, foram encontrados o Teste do Pezinho, a anamnese completa e minuciosa e o estudo genético do indivíduo. Tais métodos são eficientes para evitar equívocos durante a descoberta da doença, ao se analisar diversas características fisiológicas do paciente (Feitosa; et al, 2018).

O Teste do Pezinho é como ficou conhecido popularmente o Programa Nacional de Triagem Neonatal, implementado e obrigatório desde 1992, com o intuito de detectar algumas doenças genéticas, congênitas e metabólicas pelo Sistema Único de Saúde, a fim de se iniciar o tratamento precoce dessas doenças quando o indivíduo é portador, de modo a reduzir as chances de óbito e de deficiências, melhorando a saúde do paciente. Dentre as inúmeras doenças detectadas por esse teste, a Fibrose Cística é uma delas, tornando sua descoberta precoce uma possibilidade de iniciar o tratamento com antecedência. Esse teste é simples e de fácil realização, permitindo que os membros da família do portador de FC possam se preparar para a adequação do paciente ao tratamento durante seu crescimento (Girardet; et al, 2016).

A anamnese é o ato de coletar a história clínica do paciente de forma individualizada, cuidadosa e sigilosa, através de perguntas, da realização de análises de sinais e sintomas que o paciente está apresentando e de uma conversa sobre as patologias já ocorridas, a fim de se construir o quadro clínico e definir a doença que está acometendo o paciente. Durante anamnese de um portador de FC, além do histórico familiar para se rastrear a ocorrência na família, o médico analisa os sinais físicos do paciente e o encaminha para a realização do Teste do Suor e de outros procedimentos para a confirmação (Carvalho; et al, 2017).

Outro método utilizado para o diagnóstico da fibrose cística é o estudo genético do possível portador da doença, caracterizado como um rastreamento e sequenciamento genético que verifica se há uma desordem no gene codificador da proteína CFTR. Através da obtenção do DNA que será avaliado, o geneticista procura fazer a identificação da alteração genética que terá impacto no diagnóstico, já que é um método de suporte para confirmação, e fará o aconselhamento genético para a família. Assim, se durante a realização do sequenciamento genético, for identificado alguma das mais de 2000 mutações 
associadas ao genótipo da FC no gene da CFTR, o paciente é considerado portador da FC, entretanto a associação de outras maneiras de diagnóstico é aconselhável com a finalidade de comprovar o quadro de $\mathrm{FC}$ e de se iniciar o tratamento necessário (Santana; et al, 2020).

\section{Considerações Finais}

A fibrose cística é uma doença urgente e crônica, que faz vítimas em todo o mundo e que precisa de diagnóstico precoce, e pode ser realizado de através do Teste do Suor que é considerado padrão-ouro de identificação da fibrose cística, o Teste do Pezinho nas crianças, a anamnese e o sequenciamento genético, graças à evolução no campo da saúde, norteando as decisões terapêuticas que serão realizadas durante o tratamento.

Entender seu histórico é essencial para que o tratamento seja eficaz, já que conhecer a doença significa ter um maior suporte na luta contra as complicações da fibrose cística, além de que toda a família é envolvida no tratamento adequado do paciente.

O diagnóstico precoce pode possibilitar uma maior taxa de resposta ao tratamento, de forma a aumentar a expectativa de vida do portador de FC.

\section{Referências}

Al-Abadi, B., et al (2019). Cystic Fibrosis Gene Mutation Frequency Among a Group of Suspected Children in King Hussein Medical Center. Med Arch $73(2), 118-20$.

Adde, F. V. (2015). Nutrição em fibrose cística: tão importante quanto o manejo da doença pulmonar. Revista Paulista de Pediatria. 33(1), 1-2.

Alves, S. P. \& Bueno, D. (2018). O perfil dos cuidadores de pacientes pediátricos com fibrose cística. Ciência \& Saúde Coletiva. $23(5), 1451-7$.

Bepari, K. K., Malakar, A. K., Paul P., Halder, B. \& Chakraborty, S. (2015). Allele frequency for Cystic fibrosis in Indians vis-a/-vis global populations. Bioinformation. 11(7), 348-52

Battestin, B., et al (2016). Relato de caso: diagnóstico e manejo de paciente com fibrose cística em apresentação clássica. Revista de Medicina e Saúde de Brasília. 5(1), 66-78.

Carvalho, D. C., et al (2017). Evolução do Programa de Triagem Neonatal em hospital de referência no Ceará: 11 anos de observação. ABCS Health Sciences. 42(3), 143-46.

Cirilli, N., et al (2018). Real life pratice of sweat testing in Europe. Journal of Cystic Fibrosis. 17(3), 325-32.

Dias, A., Saatkamp, J. \& Manfredini, V. (2015). Prevalência das doenças detectadas pelo Teste do Pezinho no município de Uruguaiana, RS. Anais do Salão Internacional de Ensino, Pesquisa e Extensão. 7(2).

Domingos, M. T., Magdalena, N. I. R., Cat, M. N. L., Watanabe, A. M. \& Filho, N. A. R. (2015). Condutividade do suor e teste quantitativo coloumétrico na triagem neonatal de fibrose cística. Jornal de Pediatria. 91(6), 590-95.

Emiralioglu, N., Ozçelik, U., Yalçin, E., Dogrun, D. \& Kiper, N. (2016). Diagnosis of cystic fibrosis with chlorid meter (Sherwood M926S chloride analyzer $\left.{ }^{\circledR}\right)$ and sweat teste analysis system (CF collection system $\left.{ }^{\circledR}\right)$ compared to the Gibson Cooke method. The Turkish Journal of Peadiatrics. 58(1), 27-33.

Feitosa, M. S., et al (2018). Fibrose cística em dois irmão adultos em estado da Amazônia: estudo de caso. Revista Eletrônica Acervo Saúde.11(2).

Ferreira, D. P., Chaves, C. R. M. M. \& Costa, A. C. C. (2019). Adesão de adolescentes com fibrose cística a terapia de reposição enzimática: fatores associados. Ciência e Saúde Coletiva. 24(12).

Girardet, A. V., et al (2016). The improvement of the best pratice guidelines for preimplantation genetic diagnosis of cystic fibrosis: toward na international consensus. European Journal of Human Genetics. 24, 469-78.

Gonçalves, A. C., et al (2019). Dosagem da concentração dos íons cloreto e sódio na saliva e no suor para reconhecimento de pacientes com fibrose cística. Jornal de Pediatria. 95(4), 443-50.

Luz, G. S., Silva, M. R. S. \& DeMontigny, F. (2015). Doenças raras: itinerário diagnóstico e terapêutico das famílias de pessoas afetadas. Acta Paulista de Enfermagem. 28(5), 395-400.

Lubovich, S, et al (2019). Factores de riesgo asociados a exarcebaciones respiratórias em pacientes pediátricos com fibrosis quística. Archivos Argentinos de Pediatría. 117(5), 466-72.

Machado, L. N., Gomes, M. G. \& Alves, A. B. (2020). Relato de caso: fibrose cística e a importância do diagnóstico precoce. Revista Unilago. 1(1).

Mastella, G. (2010) Teste do suor: a análise de condutividade pode tomar o lugar do método clássico de Gibson e Cooke? Jornal de Pediatria. 586(2), 89-91. 
Research, Society and Development, v. 10, n. 3, e11710313075, 2021

(CC BY 4.0) | ISSN 2525-3409 | DOI: http://dx.doi.org/10.33448/rsd-v10i3.13075

Masson, A. A., Sampaio, L. C. \& Cavadas, A. C. S. M. (2018). Reflexões sobre o direito universal à anamnese clínica. Revista Dissertar. 1(28 e 29), 11-18.

Mendes, K. D., Silveira, R. C. \& Galvão, C. M. (2008). Integrative literature review: a research method to incorporate evidence in health care and nursing. Texto Contexto Enferm, Florianópolis. 17(4), 758-64.

Pessoa, I. L., Guerra, F. Q. S., Menezes, C. P. \& Gonçalves, G. F. (2015). Fibrose Cística: Aspectos genéticos, clínicos e diagnósticos. Brazilian Journal Of Surgery and Clinical Research. 11(4), 30-36.

Reisinho, M. C. \& Gomes, B. (2016). O adolescente com fibrose cística: crescer na diferença. Revista Portuguesa de Enfermagem de Saúde Mental. (spe3), 85-94.

Salvatore, M., et al (2017). Italian external quality assessment program for cystic fibrosis sweat chloride test: a 2015 and 2016 results comparison. Ann Ist Super Sanita. 53(4), 305-13

Santana, N. N. S., Silva, C. D. A., Mota, M. A. G., Freitas, B. A., Soares, A. M. (2020). Análise descritiva dos pares de mutações da proteína CFTR e estado funcional de adolescentes com fibrose cística: uma série de casos. Revista Inspirar. 20(1), 1-13.

Servidoni, M. F., et al (2017). Teste do suor e fibrose cística: panorama da realização do teste em centros públicos e privados de São Paulo. Jornal Brasileiro de Pneumologia. 43(2), 121-8.

Souza, R. P., et al (2018). O uso da ultrassonografia para avaliar a espessura muscular e a gordura subcutânea em crianças e adolescentes com fibrose cística. Revista Paulista de Pediatria. 36(4), 457-65.

Terlizzi, V., et al (2018). Clinical expression of cystic fibrosis in a large cohort of Italian siblings. BMC Pulm Med 18, 196. 